\title{
An approach to the landscape analysis
}

\author{
B. Badiani \\ Researcher of Urban and Regional Planning, \\ University of Brescia, Italy
}

\section{Abstract}

The starting-point is the new conception of landscape proposed by the European Convention on Landscape (Florence, 2000): the landscape is a combination of elements, natural and not, that encircle us.

In light of this new concept, the work proposes a reflection on the actual modalities of the description and interpretation of the landscape used as the first step in environmental planning.

In 2002, the Lombardia region approved a law concerning the guide lines for the examination of the projects in relation with the landscape value. So it is very important to make clear what a landscape means. But the elements suggested in this law to describe the landscape do not seem to be useful in estimating its value.

Taking into account the proposed methodologies of this regional law, an attempt has been made to devise one practical and flexible procedure for the evaluation of the characters of the landscape.

The aim is to reach a fundamental knowledge of what a landscape is, taking into account its concrete and sensitive aspects and their possible descriptions.

The methodology is based on a check-list of natural and human elements, implemented on a GIS. A database has been associated with each element. The information put into the database is organized in a way to facilitate the evaluation of the landscape, the communication of the result of the analysis and the participation of the citizens in the decisional phase.

The methodology has been applied to a territory of a municipality in Northern Italy to test the good flexibility, the simplicity and the clarity of the description of the landscape image and the improvement of the quality and completeness of the check-lists.

Keywords: landscape analysis, environmental planning, landscape planning, GIS. 


\section{Introduction}

Safeguarding the landscape mainly entails governing its transformations due to the action of man or natural events. This translates into the fact that each landscape and territorial policy initiative must therefore originate from tools useful to govern the transformations.

According to the National legislation referring to the Natural Heritage and Landscape Code, approved as Legislative Decree No. 42 dated 22nd January 2004 and that came into force on 1st May 2004, the urban municipal plan is assigned a special conclusive value in the process to construct the overall safeguarding system, as also expressly stated in the regional law of Lombardy No. 12 dated 15th March 2005 "Law to govern the territory", requiring the foregoing planning tool to also include landscape-related aspects.

The following aspects emerged from an analysis of the initial experiences of local landscape planning:

○ the lack of a simple, effective, easily applied and above all shared operating methodology, with the consequent limited tangible use of the tool;

- a lack of clarity and precision in describing the criteria used to determine the classes of sensitivity of the local landscape;

- a limited or no participation and involvement of the local community in the preparatory phases of the Plans and when determining the classes of sensitivity of the landscape;

- no consideration has been given to shared tangible and schematic parameters or indicators, as a tool to analyse and evaluate the landscape.

The fundamental methodological aspects of the proposed method have been defined starting from this critical verification. The method must be:

- $\quad$ concise $\rightarrow$ a limited number of parameters to be assessed;

- readily understandable and applicable $\rightarrow$ clear, well-defined and practical;

- $\quad$ general and flexible $\rightarrow$ applicable to different territorial environments without too many difficulties;

- $\quad$ easy to manage $\rightarrow$ based on readily obtainable data;

- $\quad$ effective and useful $\rightarrow$ which enables tangible results to be attained.

However, the starting point remains the clarity of the concepts and the objectives which are to be achieved. Therefore, it is essential to specify what is meant by landscape, which of the infinite definitions and interpretations of the term is taken into consideration in relation with the scope of the methodology proposed.

It was deemed appropriate to consider the concept of landscape proposed by the European Convention (Florence, 2000), since it has been formulated recently, incorporates various aspects addressed in previous years and expresses the complex nature of the concept in the best possible way.

The landscape is everything that surrounds us and that we perceive with our eyes and with our emotions, and more in detail it is "a determined portion of territory which is perceived by man, the appearance of which is the result of the 
action of human and natural factors and of their interrelations [...] a shared asset, the basis of the cultural and local identity of populations, an essential component of the quality of life and expression of the richness and diversity of the cultural, ecological, social and economic heritage". In this sense we can interpret the landscape as the series of signs left on the territory by natural and human history, read and interpreted by an observer.

And it is at this point that the main problem to be addressed is encountered: if the landscape is "everything", how can a practical procedure be found that takes into consideration each constituent feature? How can such an ambiguous concept be rendered concise and schematic?

There is a need to deliberately limit the analysis of the landscape by considering the most significant and important aspects for its planning and management. But what is significant in a landscape? To make a selection among the features which surround us entails a choice that is undoubtedly arbitrary and subjective. Furthermore, in this way the understanding of the landscape will never be complete, because some factors or aspects that could be significant will always be excluded.

A possible solution exists if one observes that complexity is a factor which cannot be eliminated in order to know the landscape, and it is pointless to try to understand everything. It is necessary to be aware of the fact that an "approximate knowledge" exists.

\section{Presentation of the proposed procedure}

The method that is illustrated below intends to foster the awareness of both the designer and the local populations as regards safeguarding the landscape and can be a useful help in landscape planning at the municipal level.

The methodological path is characterised in stages:

1. a first stage to identity the objectives associated with the;

2. an analysis stage, based on collecting data and processing the data in a reference list;

3. an assessment stage, which entails describing the aspects which combine to attributing value to the features identified as being characterising features;

4. drawing up a landscape map, which is created by using GIS (Geographical Information System) software, which enables some alphanumeric information to be associated with the graphic elements represented, thanks to the use of a descriptive database that contains information regarding the features necessary to appreciate the landscape's overall value.

\section{Landscape analysis stage}

The scale of the intervention is selected, which in this case is on a municipal scale, after having defined the objective of the landscape analysis, which could 
be to identify the special local features in order to verify the sensitivity to changes associated with planning choices.

The processing activity consists in selecting the data collected. The most important factors to be considered in the analysis stage are outlined in the following list, which can be enriched and extended:

1. physical and natural features;

2. anthropic features: these represent the landscape components that derive from the action of man;

3. perception features: these represent the landscape components subject to perception;

4. critical areas: these represent factors which identify particular situations.

The check-list structured in this way includes all the landscape features considered to be most significant and above all shared. This has been possible by involving the local community, also in the stage of preparing the checklist. Table 1 shows a number of the items adopted, for purposes of illustration.

A value must be assigned after the landscape has been analysed and after all its constituent factors have been identified. This entails defining criteria to establish an opinion about the single feature. This represents an extremely subjective and delicate operation.

In this session it was deemed more important to define the aspects of the feature that can contribute to establishing the value.

An attempt was made to break down the feature into its fundamental aspects to appreciate fully all the aspects that can influence the value of a given feature. The concepts of shape, meaning and use were selected.

First of all, a landscape feature is characterised by a shape, which represents its physical constitution, its aesthetic features such as size, colours, contours, etc. The value opinion in relation to the shape can depend on the presence of rare or unusual features, the diversity and variety of the features, their integration, etc.

The meaning is the result of the individual's perception and is influenced by a series of interrelationships which are established among the object, the surrounding context and the person making the assessment. The relationship with the objective of the analyses must also be established to assess the meaning. The following criteria have been identified:

- $\quad$ Readability $\rightarrow$ meaning the quality that confers on a feature of the landscape a high probability of evoking a well identified, structured and functional environmental image in an observer;

- $\quad$ Use $\rightarrow$ has a dual meaning. To be understood as the possibility of using the feature in question or the possibility of using other features via this feature;

- Context $\rightarrow$ represents the set of features that surround the feature under examination and can be "natural", or "man-made";

- Visual $\rightarrow$ is understood as the type of view presented by observing the landscape feature in its context;

- Value $\rightarrow$ this term is associated with the social and cultural aspects and with the local history, as well as the importance of the landscape heritage; 
- $\quad$ State $\rightarrow$ this term refers to the degree of naturalness and integrity of a given feature.

Table 1: $\quad$ Brief description of the landscape features and the data sources.

\begin{tabular}{|c|c|c|}
\hline Feature & Brief description & Sources \\
\hline \multicolumn{3}{|c|}{ NATURAL FEATURES } \\
\hline $\begin{array}{l}\text { Mountain, ridge } \\
\text { surveys }\end{array}$ & $\begin{array}{c}\text { Represent the watershed lines } \\
\text { of the principal catchment } \\
\text { basin. }\end{array}$ & $\begin{array}{c}\text { Technical regional } \\
\text { map }\end{array}$ \\
\hline Morphological factors & $\begin{array}{c}\text { Characteristic forms of the } \\
\text { land due to past or current } \\
\text { morphological } \\
\text { transformations. }\end{array}$ & $\begin{array}{c}\text { Technical regional } \\
\text { map }\end{array}$ \\
\hline \multicolumn{3}{|c|}{ ANTHROPIC FEATURES } \\
\hline $\begin{array}{l}\text { Historical centres and } \\
\text { settlements }\end{array}$ & $\begin{array}{c}\text { Built-up areas which represent } \\
\text { the oldest district of the urban } \\
\text { system. }\end{array}$ & $\begin{array}{c}\text { Municipal } \\
\text { cartography } \\
\text { Historical archives }\end{array}$ \\
\hline \multicolumn{3}{|c|}{ PERCEPTION FEATURES } \\
\hline Panoramic views & $\begin{array}{c}\text { Visual overviews of shared } \\
\text { importance }\end{array}$ & \multirow{3}{*}{$\begin{array}{l}\text { Municipal and } \\
\text { provincial } \\
\text { cartography } \\
\text { Site visits }\end{array}$} \\
\hline Panoramic points & $\begin{array}{c}\text { Place from which it is } \\
\text { possible to enjoy a panoramic } \\
\text { view }\end{array}$ & \\
\hline $\begin{array}{l}\text { Routes to enjoy the } \\
\text { landscape }\end{array}$ & $\begin{array}{c}\text { Road or footpaths, pedestrian- } \\
\text { bicycle lanes and routes from } \\
\text { which the landscape can be } \\
\text { enjoyed }\end{array}$ & \\
\hline \multicolumn{3}{|c|}{ CRITICAL AREAS } \\
\hline Degraded areas & Areas subject to change & $\begin{array}{l}\text { Municipal } \\
\text { documents and } \\
\text { cartography } \\
\text { Site visits }\end{array}$ \\
\hline
\end{tabular}

The function is associated with the how the feature is used. The function aspect is associated with a value related to the following criteria, as in the case of the meaning assessment:

- Accessibility $\rightarrow$ this represents the possibility of reaching the landscape feature, therefore of enjoying it and exploiting it from the recreational or useful point of view;

- Use $\rightarrow$ this is understood as the use of the land referred to the area in which landscape feature under examination is located;

- Profitability $\rightarrow$ this refers to the possibility of generating income associated with the landscape feature as a tourist venue or as a source of commercial resources or again as a place for recreation. 
The most obvious and important novelty introduced by the methodology proposed, consists in characterising the landscape features directly at the cartographic level: the features are not only represented by locating them on the map, but an assessment is also associated with them through a combination of symbols associated with the aspects which define their value.

Some examples of the map detailing the shape, meaning and function aspects of a number of features that constitute the landscape are shown in the illustrations below.
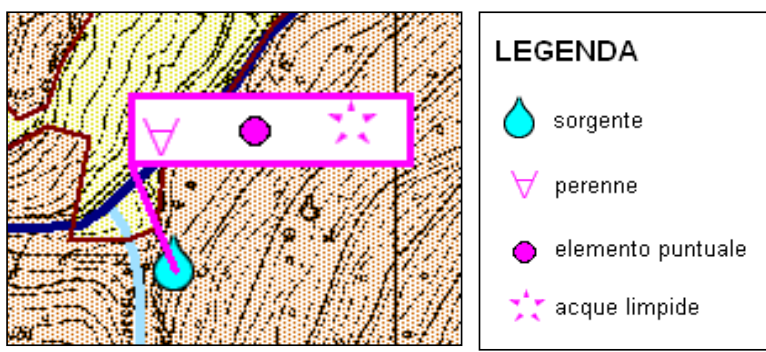

Figure 1: $\quad$ Shape table.
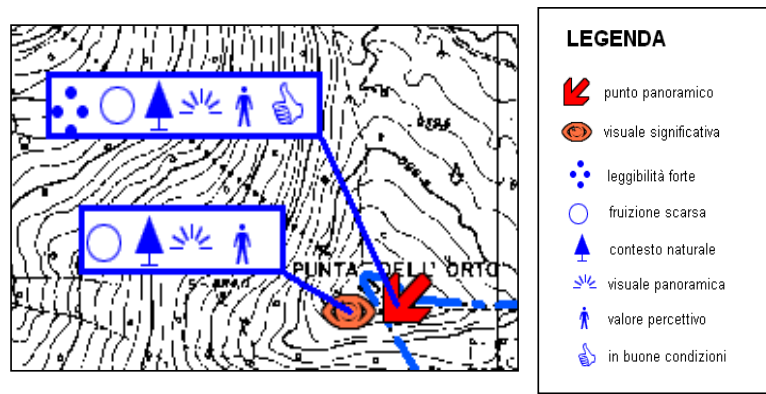

\section{LEGEND}

- panoramic point

- significant view

- strong readability

- limited use

- natural context

- panoramic view

- perceptive value

- in good conditions

Figure 2: Meaning table.

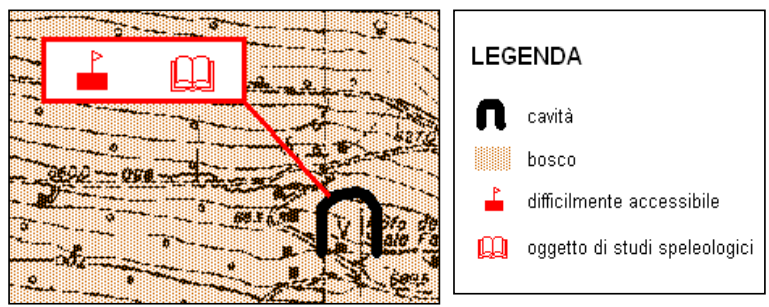

\section{LEGEND}

- hollow

- wood

- difficult access

- object of speleological studies

Figure 3: Function table. 


\section{Conclusions}

An attempt has been made to create a practical and flexible procedure to assess the quality of the landscape, using on a knowledge database to manage the territorial transformations by referring to the methodologies and the operating methods proposed by the regional regulations which relate to landscape planning and managing landscape transformations, and their application to a number of municipal territorial contexts, (in particular the guidelines for landscape-related examination of projects, approved with Regional Council Resolution (D.G.R.) No. 7/11045 dated 8th November 2002).

The starting point of this study is represented by the endeavour to establish an in-depth knowledge of the landscape features, to focus attention on the most tangible and sensitive aspects and on their possible representation.

The greatest difficulty found was associated with the need to represent the landscape concisely, without reducing the significance and complexity.

The landscape is analysed by specifying its shape, its meaning and its function and the methodology proposed enables its potential, values and criticalities to be interpreted.

The procedure proposed has been applied to a case study: the Municipality of Polaveno, located in North Italy (Province of Brescia) and a number of aspects worthy of note have been highlighted. On the one hand, problems and difficulties emerged due to the limits of the form to represent the landscape that is necessarily partial. On the other hand new potential for new fields of application have emerged.

The need to make significant choices regarding the features to be taken into consideration stems from the impossibility of representing "everything". In relation to the objective that is to be achieved, the best and most effective criteria to be adopted in making this selection, is undoubtedly the criteria of interpreting the landscape based on the social perception of the persons that benefit directly from the landscape.

Difficulties were experienced in retrieving all the useful information, both with reference to the location of the landscape features, as well as to determine their meaning. The available and up-to-date cartographic sources are very limited. The best solution is to verify the landscape features by site visits, and above all to become acquainted through the eyes of those that live there and benefit from the landscape directly every day.

The methodology proposed does not impose any rigid schemes. Using flexible check-lists becomes a simple reference and a guide in the selection of the features which describe the landscape and for their assessment.

It was found useful to exploit the advantages and the potential offered by the GIS (Geographical Information System) digital tool to be able to consider the continuous transformations of the built up landscape framework, in the best possible way.

The data collected and summarised can be changed or consulted at any time, also solving the problem of updating the maps. 
348 Geo-Environment and Landscape Evolution II

\section{References}

[1] R.Arnheim, La dinamica della forma architettonica, Feltrinelli, Milano, 1981

[2] B.Badiani, Movimento e qualità dello spazio urbano, Ed. Bios, Cosenza, 2004

[3] A.Clementi, Revisioni di paesaggio, Meltemi ed., 2002

[4] J. Gehl, Vita in Città: spazio urbano e relazioni sociali, Maggioli Editore, Rimini, 1999

[5] C.Lévy-Leboyer, Psicologia dell'ambiente, Laterza, Bari, 1982

[6] A.Sestini, Il paesaggio, TCI, Milano, 1963

[7] F.Steiner, Costruire il paesaggio. Un approccio ecologico alla pianificazione, McGraw-Hill, 2004

[8] L. Quaroni, Il volto della città, in Comunità n.25, 1954

[9] M.Tira (a cura di), Metropoli e mobilità: il caso di Brescia, vol.4, Sintesi Ed., Brescia 1996 